\title{
Effect of Microstructure on Torsional Fatigue Endurance of Martensitic Carbon Steel*
}

\author{
Shunsuke TOYODA**, Yasuhide ISHIGURO**, Yoshikazu KAWABATA**, \\ Kei SAKATA**, Akio SATO** and Jun'ichi SAKAI*** \\ ** JFE Steel Corporation \\ Kawasaki-cho 1-1, Handa, Aichi 475-8611 Japan \\ E-mail:s-toyoda@jfe-steel.co.jp \\ *** Faculty of Science and Engineering, Waseda University \\ Okubo 3-4-1, Shinjuku-ku, Tokyo, 169-8555 Japan
}

\begin{abstract}
The microstructural influence of martensitic carbon steel on torsional fatigue endurance was investigated, taking into consideration the application of high strength steel electric resistance welded (ERW) tubes to automotive structural parts. The chemical composition of the base steel alloy was $0.1-0.2 \% \mathrm{C}-0.2-1.5 \% \mathrm{Si}$ $1.3-1.9 \% \mathrm{Mn}-0.01 \% \mathrm{P}-0.001 \% \mathrm{~S}-(\mathrm{Cr}, \mathrm{Mo}, \mathrm{Ti}, \mathrm{Nb}, \mathrm{B})$. Laboratory vacuum-fused ingots were hot-rolled, heated to 1023 or $1223 \mathrm{~K}$ in a salt bath, and then waterquenched and tempered at $473 \mathrm{~K}$. Consequently, three types of microstructure, martensite $(\mathrm{M})$, martensite and ferrite $(\mathrm{M}+\mathrm{F})$, and ferrite and pearlite $(\mathrm{F}+\mathrm{P})$, were prepared. Fully reversed torsional fatigue testing was conducted with $6 \mathrm{~mm}$ diameter round bar specimens. Torsional fatigue endurance was found to monotonously increase with increases in the tensile strength of the specimen from 540 to $1380 \mathrm{MPa}$. The martensitic single structure and the $\mathrm{M}+\mathrm{F}$ dual-phase structure showed a similar level of fatigue endurance at a tensile strength of approximately $950 \mathrm{MPa}$. However, fatigue micro-crack morphology varied slightly between them. At the surface of the $\mathrm{M}+\mathrm{F}$ specimen, many small cracks were observed in addition to the main crack. Conversely, in the martensitic specimen, these small cracks were rarely observed. $\Delta K$ decreasing/increasing crack growth testing with compact tension (CT)-type specimens was also conducted. Based on these experimental results, the effect of microstructure and stress level on the initiation/propagation cycle ratio is discussed. In addition to fatigue properties, some practical properties, such as low-temperature toughness and hydrogen embrittlement resistance, were also evaluated in view of actual applications for automotive structural parts.
\end{abstract}

Key words: Torsional Fatigue Test, Crack Growth Rate, Martensite, Microstructure, High Strength Carbon Steel, Low-Temperature Toughness, Hydrogen Embrittlement

\section{Introduction}

In order to reduce the weight and size of suspension parts, steel tubes have increasingly been used in recent years ${ }^{(1)-(3)}$. When particularly high static strength and fatigue endurance are required, quenching, i.e., using a martensitic microstructure, is an effective method of strengthening. The effect of microstructure on the fatigue endurance of steel has been intensively investigated. Kurita $e t$ al. examined the effect of strengthening mechanisms on the fatigue endurance of $\mathrm{F}+\mathrm{P}$ and $\mathrm{F}+\mathrm{M}$-based microstructures under tension-compression 
axial loading ${ }^{(4)(5)}$. Wang et al. studied the effect of martensite volume fraction and morphology on the fatigue crack growth rate of a $\mathrm{F}+\mathrm{M}$ microstructure under tension-zero cycling ${ }^{(6)(7)}$. However, the microstructural influence of $800 \mathrm{MPa}$ and higher tensile strength grade steel on fatigue endurance has not been fully clarified yet.

In this study, we conducted torsional fatigue and CT-type crack growth tests on $0.1-0.2 \% \mathrm{C}-0.2-1.5 \% \mathrm{Si}-1.3-1.9 \% \mathrm{Mn}-0.01 \% \mathrm{P}-0.001 \% \mathrm{~S}-(\mathrm{Cr}, \mathrm{Mo}, \mathrm{Ti}, \mathrm{Nb}, \mathrm{B})$-based

martensitic high-tensile strength steels. Based on these experimental results, the effects of microstructure and stress level on the initiation/propagation cycle ratio are discussed.

\section{Nomenclature}

$\begin{array}{llll}a_{i} & \text { initial fatigue crack length } & N_{c} & \text { crack propagation cycle number } \\ a_{c} & \text { final fatigue crack length } & R & \text { stress ratio } \\ C & \text { crack growth law coefficient } & s & \text { crack length } \\ d a / d N & \text { crack growth rate } & V_{f} & \text { volume fraction of ferrite } \\ d_{f} & \text { ferrite grain size } & \Delta K & K_{\max }-K_{\min } \text { in a fatigue cycle } \\ d_{m p} & \text { martensite packet size } & \Delta K_{t h} & \text { threshold stress intensity factor range } \\ F & \text { correction factor } & \Delta \sigma & \text { nominal stress } \\ m & \text { crack growth exponent } & \rho & \text { notch root radius }\end{array}$

\section{Experimental}

The chemical compositions of the steels used in this study are listed in Table 1, along with the desired microstructure ${ }^{(8)}$. $\mathrm{Cr}, \mathrm{Mo}, \mathrm{Ti}, \mathrm{Nb}$, and $\mathrm{B}$ were arbitrarily added in order to adjust the hardenability and grain size of the specimens. Figure 1 shows the hot-rolling and heat-treatment conditions of the specimens. Laboratory vacuum-fused ingots were hot-rolled, and then one was heated to the austenite-ferrite dual-phase region at $1023 \mathrm{~K}$ while the other was heated to the austenite region at $1223 \mathrm{~K}$ in a salt bath. Both were immediately water-quenched and subsequently tempered at $473 \mathrm{~K}$. As shown in Fig. 2, three types of microstructure, martensite $(\mathrm{M})$, martensite and ferrite $(\mathrm{M}+\mathrm{F})$, and ferrite and pearlite $(\mathrm{F}+\mathrm{P})$, were prepared after the heat treatment. The material heated to the austenite-ferrite dual-phase region, $\mathrm{MF}$, shows the martensite and ferrite structure (volume fraction of ferrite, $V_{f}=45 \%$; ferrite grain diameter, $d_{f}=20 \mu \mathrm{m}$ ), while the material heated to the austenite region, M1-M3, exhibits the martensite structure (martensite packet diameter, $\left.d_{m p}=10 \mu \mathrm{m}\right)$. The ferrite and pearlite structure $\left(V_{f}=76 \%\right.$; ferrite grain diameter, $\left.d_{f}=30 \mu \mathrm{m}\right)$ is an as-hot-rolled material used for comparison (FP1). Microstructural anisotropy and band structure were not observed in these specimens. Table 2 shows the tensile properties and volume fraction of microstructure of the specimens. The tensile strength varied from 540 to $1380 \mathrm{MPa}$.

Figure 3 shows the round bar-type torsional fatigue test specimen with a $6 \mathrm{~mm}$ diameter and a $15 \mathrm{~mm}$ long parallel portion. Torsional fatigue characteristics were evaluated under a stress ratio of $R=-1$ and a repetition rate of $33 \mathrm{~Hz}$. The surface was machine-finished. Scanning electron microscope (SEM) observation was conducted on a cross-section of the surface of the round bar specimen after the fatigue test. The surface was etched with $2 \%$ Nital. Transmission electron microscope (TEM) observation was carried out for some samples after the fatigue test.

$\Delta K$ decreasing/increasing crack growth tests were carried out with separately prepared CT-type specimens, as shown in Fig. 4. The crack growth test was performed under sinusoidal loading at a frequency of $15 \mathrm{~Hz}$ with a stress ratio of $R=0.1$. Table 3 shows the Vickers hardness and microstructure of the crack growth test specimens. The chemical composition is the same as for FP1 and M3 in Table 1. Hot-rolling and heat-treatment 
Table 1 Chemical composition of steel used.

\begin{tabular}{|c|c|c|c|c|c|c|}
\hline \multirow[t]{2}{*}{ Material } & & Chemica & al com & positic & (mass \%) & \multirow{2}{*}{$\begin{array}{c}\text { Microstructure } \\
\text { [aim] }\end{array}$} \\
\hline & $\mathrm{C}$ & $\mathrm{Si} \mathrm{Mn}$ & $\mathrm{P}$ & $\mathrm{S}$ & Others & \\
\hline FP1 & 0.18 & $\begin{array}{ll}0.2 & 1.3\end{array}$ & 0.01 & 0.001 & $\mathrm{Cr}, \mathrm{Ti}, \mathrm{Nb}, \mathrm{B}$ & $\mathrm{F}+\mathrm{P}$ \\
\hline MF & 0.13 & 1.51 .9 & 0.01 & 0.001 & $\mathrm{Cr}, \mathrm{Mo}, \mathrm{Ti}, \mathrm{Nb}$ & $\mathrm{M}+\mathrm{F}$ \\
\hline M1 & 0.10 & $0.4 \quad 1.9$ & 0.01 & 0.001 & $\mathrm{Cr}, \mathrm{Mo}, \mathrm{Ti}, \mathrm{Nb}$ & \multirow{3}{*}{ M } \\
\hline M2 & 0.14 & 0.41 .9 & 0.01 & 0.001 & $\mathrm{Cr}, \mathrm{Mo}, \mathrm{Ti}, \mathrm{Nb}$ & \\
\hline M3 & 0.18 & $\begin{array}{ll}0.2 & 1.3\end{array}$ & 0.01 & 0.001 & $\mathrm{Cr}, \mathrm{Ti}, \mathrm{Nb}, \mathrm{B}$ & \\
\hline
\end{tabular}

Heat-treatment specimen size in a salt bath $\cdot 25^{\mathrm{t}} \times 25^{\mathrm{L}} \times 150^{\mathrm{W}} \mathrm{mm}$ (for torsional fatigue test) $\cdot 12^{\mathrm{t}} \times 70^{\mathrm{L}} \times 100^{\mathrm{W}} \mathrm{mm}$ (for CT type crack growth test)



Fig. 1 Hot-rolling and heat-treatment condition.

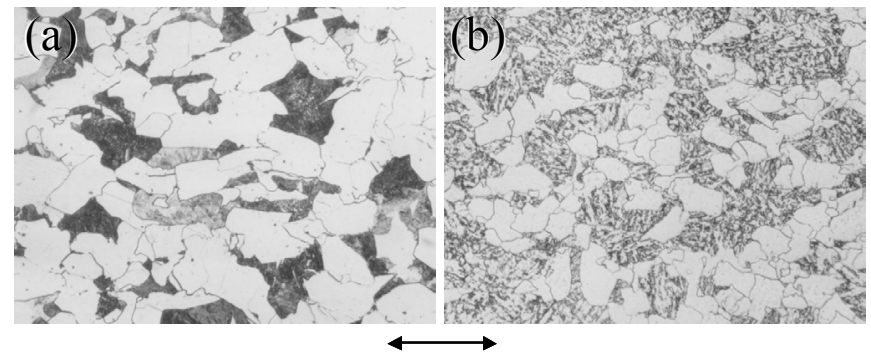

Hot-rolling direction

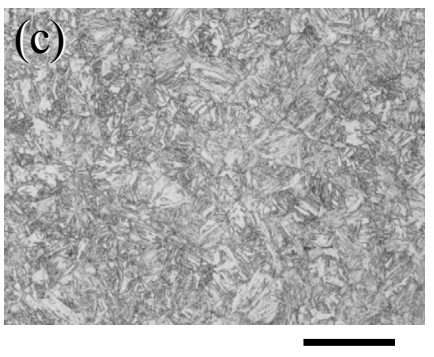

$\mathbf{5 0} \mu \mathrm{m}$

Fig. 2 Optical micrographs of heat-treated specimens for torsional fatigue test; (a) TS $540 \mathrm{MPa}$ ferrite and pearlite (FP1), (b) TS $920 \mathrm{MPa}$ martensite and ferrite (MF), (c) TS $1380 \mathrm{MPa}$ martensite microstructure (M3).

Table 2 Tensile properties and volume fraction of microstructure of specimens.

\begin{tabular}{|c|c|c|c|c|c|c|}
\hline \multirow[b]{2}{*}{ Material } & \multicolumn{4}{|c|}{ Tensile properties ${ }^{*}$} & \multirow[b]{2}{*}{$\begin{array}{l}\text { HV } \\
\text { (10) }\end{array}$} & \multirow[b]{2}{*}{ Microstructure } \\
\hline & $\begin{array}{c}\text { YS } \\
(\mathrm{MPa})\end{array}$ & $\begin{array}{c}\mathrm{TS} \\
(\mathrm{MPa})\end{array}$ & $\begin{array}{l}\text { YR } \\
(\%)\end{array}$ & $\begin{array}{l}\text { El } \\
(\%)\end{array}$ & & \\
\hline FP1 & 340 & 540 & 63 & 34 & 157 & $\mathrm{~F}+\mathrm{P}\left(V_{f}=76 \%, d_{f}=30 \mu \mathrm{m}\right)$ \\
\hline MF & 690 & 920 & 75 & 18 & 274 & $\mathrm{M}+\mathrm{F}\left(V_{f}=45 \%, d_{f}=20 \mu \mathrm{m}\right)$ \\
\hline M1 & 720 & 970 & 75 & 17 & 313 & \multirow{3}{*}{$\mathrm{M}\left(d_{m p}=10 \mu \mathrm{m}\right)$} \\
\hline M2 & 890 & 1170 & 76 & 12 & 359 & \\
\hline M3 & 1110 & 1380 & 80 & 13 & 442 & \\
\hline
\end{tabular}

conditions are indicated in Fig. 1. The crack growth direction was transverse to the hot-rolling direction. In the crack growth test, a stepwise $\Delta K$ decreasing procedure was used to obtain the threshold value. The threshold stress intensity factor range, $\Delta K_{t h}$, was determined as the $\Delta K$ at which no crack growth was observed for $2 \times 10^{6}$ cycles. Subsequently, a $\Delta K$ - increasing test was conducted to obtain the entire crack growth curve. 
The initial fatigue crack length was $12 \mathrm{~mm}$ and the initial $\Delta K$ value was $22 \mathrm{MPa} \sqrt{\mathrm{m}}$. Prior to the fatigue crack test, the specimen surface was etched with $2 \%$ Nital to allow for in-situ crack growth observation with an optical microscope.

\section{Results and Discussion}

Figure 5 shows the relationship between stress amplitude and fatigue endurance in the torsional fatigue test. Monotonous improvement of fatigue endurance is obtained by an increase in tensile strength in the range from 540 to $1380 \mathrm{MPa}$. M1 and MF, both having a tensile strength of about $950 \mathrm{MPa}$, show almost the same fatigue endurance independent of the loading stress level.

Figure 6 shows SEM micrographs of a cross-section at the surface of the round bar specimen after the torsional fatigue test. At the surface of the FP1 and MF specimens, many small cracks were observed in addition to the main crack. Conversely, these small cracks were rarely observed at the surface of the martensite single structure specimen.

Figure 7 shows SEM micrographs of a cross-section at the surface along main cracks. The main cracks of the $\mathrm{F}+\mathrm{P}$ and $\mathrm{M}+\mathrm{F}$ dual-phase specimens have propagated irrespective of microstructure except at the surface.

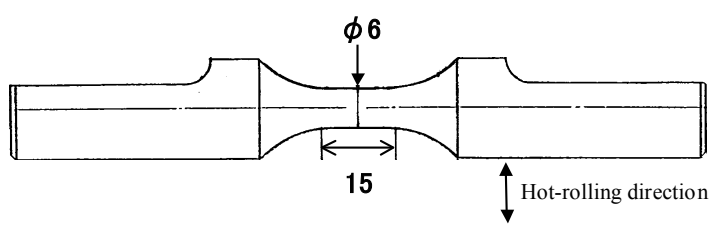

Fig. 3 Round bar-type torsional fatigue test specimen.



Fig. 4 CT-type crack growth test specimen $\left(9.5 \mathrm{~mm}^{\mathrm{t}}\right)$.

Table 3 Vickers hardness and microstructure of the crack growth test specimens.



Fig. 5 Relationship between stress amplitude and fatigue endurance in the torsional fatigue test. 


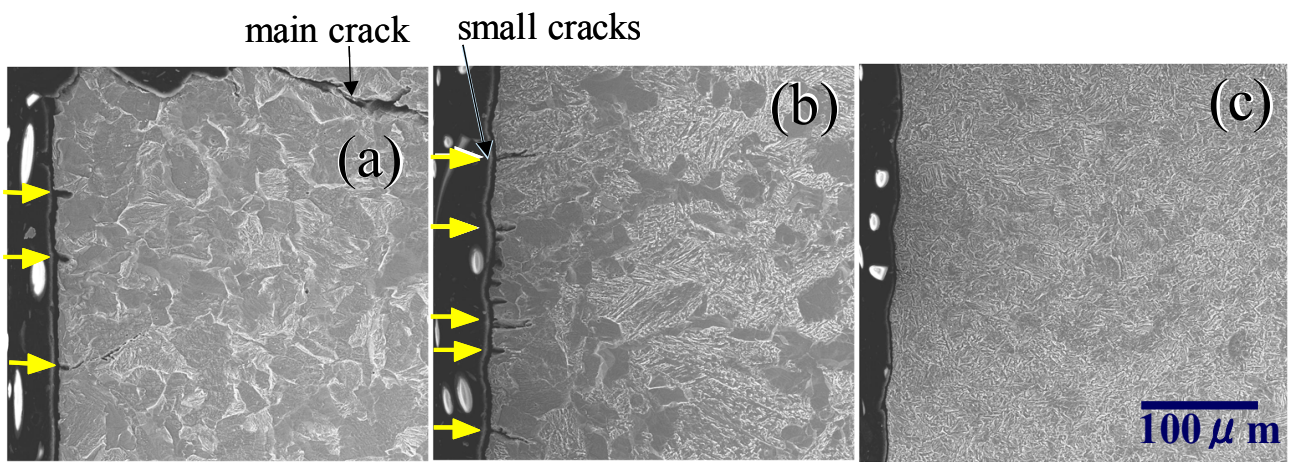

Fig. 6 SEM micrographs of a cross-section at the surface of the round bar specimen after the torsional fatigue test; (a) TS $540 \mathrm{MPa}$ ferrite and pearlite (FP1) at $\tau= \pm 400 \mathrm{MPa}$ to $N=8000$ cycles, (b) TS $920 \mathrm{MPa}$ martensite and ferrite (MF) at $\tau= \pm 500 \mathrm{MPa}$ to $N=7000$ cycles, (c) TS $970 \mathrm{MPa}$ martensite (M1) at $\tau= \pm 500 \mathrm{MPa}$ to $N=9000$ cycles.
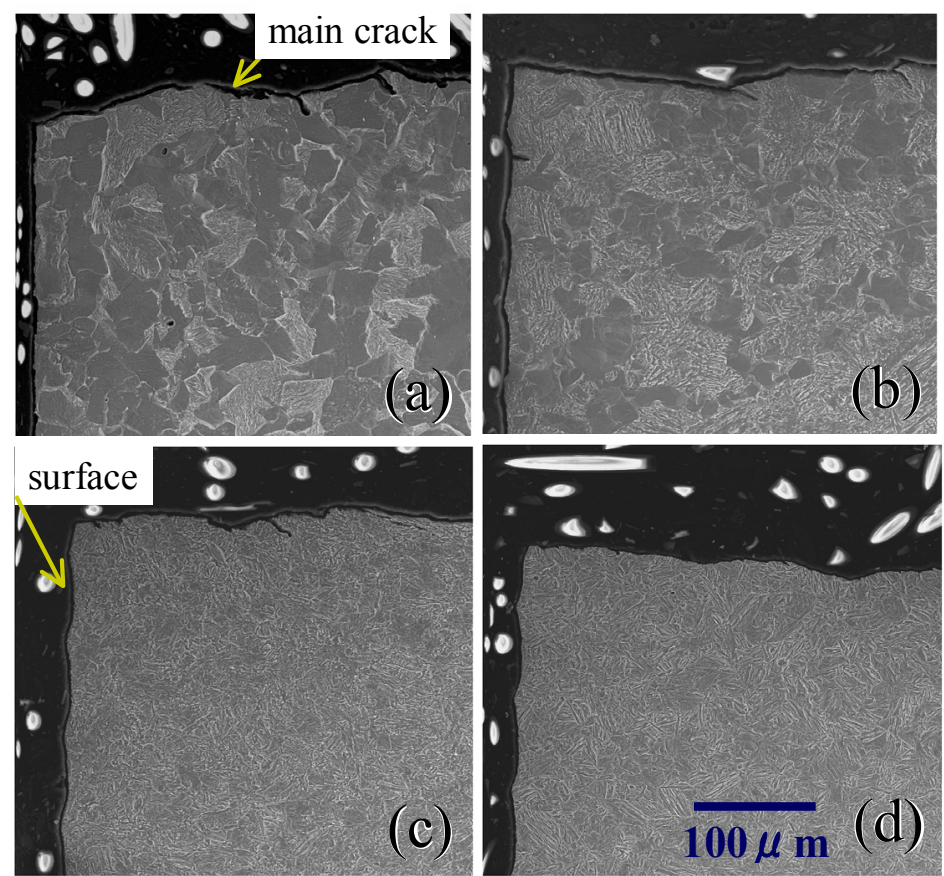

Fig. 7 SEM micrographs of a cross-section at the surface along main cracks; (a) TS 540 MPa ferrite and pearlite (FP1) at $\tau= \pm 250 \mathrm{MPa}$ to $N=2.03 \times 10^{5}$ cycles, (b) TS $920 \mathrm{MPa}$ martensite and ferrite (MF) at $\tau= \pm 500 \mathrm{MPa}$ to $N=7000$ cycles, (c) TS $970 \mathrm{MPa}$ martensite (M1) at $\tau= \pm 500 \mathrm{MPa}$ to $N=$ 9000 cycles, (d) TS $1380 \mathrm{MPa}$ martensite (M3) at $\tau= \pm 600 \mathrm{MPa}$ to $N=41000$ cycles.

Figure 8 shows SEM macro- and micrograph on the surface of the TS 540MPa ferrite and pearlite (FP1) specimen. The cracks initiated in the ferrite grain and propagated parallel and perpendicular to the axial directions that were the same as maximum shear stress direction. Then, the cracks branched to the maximum tensile stress direction. The cracks of the TS 920MPa martensite and ferrite (MF) specimen also initiate in ferrite grain (arrows in Fig. 9 (b)) and then branched. The cracks of the TS $970 \mathrm{MPa}$ martensite (M1) also indicate initiation in the shear stress direction and branching (shown in Fig. 10). However, the number of initiated cracks and the ratio of branched element seems to be smaller than in the FP1 and MF specimens. On the surface of the TS 1380MPa martensite (M3) specimen, the surface micro cracks were rarely observed, as shown in Fig. 11. The influence of stress level on crack path has not been observed in these specimens.

Figure 12 shows SEM macrographs of fracture surface. The cracks propagated mainly perpendicular to the axis direction; however, microscopically, the cracks also have an 




Fig. 8 SEM micrograph on the surface of the TS $540 \mathrm{MPa}$ ferrite and pearlite (FP1) specimen at $\tau=$ $\pm 300 \mathrm{MPa}$ to $N=55000$ cycles.



Fig. 9 SEM micrograph on the surface of the TS 920 MPa martensite and ferrite (MF) specimen at $\tau$ $= \pm 400 \mathrm{MPa}$ to $N=47000$ cycles.

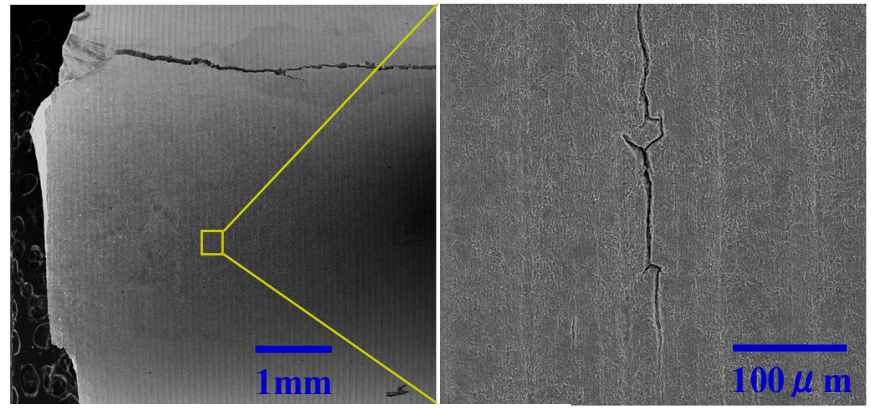

Fig. 10 SEM micrograph on the surface of the TS $970 \mathrm{MPa}$ martensite (M1) specimen at $\tau= \pm 400$ MPa to $N=34000$ cycles.

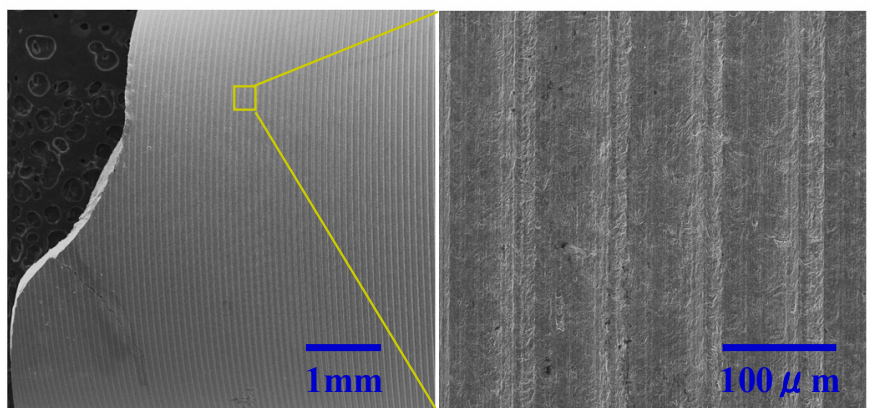

Fig. 11 SEM micrograph on the surface of the TS $1380 \mathrm{MPa}$ martensite (M3) specimen at $\tau= \pm 500$ MPa to $N=1.11 \times 10^{5}$ cycles.

inclined direction element, which is also observed in the macrographs of Fig. 8 - Fig. 11 . Crack coalescence also occurred on the way to final fracture.

Figure 13 shows the TEM micrograph near the surface of the M1 specimen after a torsional fatigue test. It shows the typical dislocation cell structure similar to that observed in a soft ferrite matrix after fatigue testing in previous studies ${ }^{(5)(7)}$.

Figure 14 shows $d a / d N-\Delta K$ curves of the FP2, FM, and M4 specimens. The threshold 




Fig. 12 SEM macrographs of fracture surface.

stress intensity factor range, $\Delta K_{\text {th }}$, value decreased slightly from 10 to $8 \mathrm{MPa} \sqrt{ } \mathrm{m}$ with an increase in hardness of the specimen. This may be due to the decrease of plastic formability at the crack tip. Regression lines of the $d a / d N-\Delta K$ curves are re-plotted in Fig. 15.

To consider the reason why specimens FM and M1 show almost the same fatigue endurance independent of the loading stress level, the propagation cycle number was estimated by the Paris law as follows:

$$
\frac{d a}{d N}=C(\Delta K)^{m}
$$

where $C$ and $m$ are material constants.

The crack propagation cycle number, $N_{c}$, can then be derived from following equation:

$$
\begin{gathered}
N_{C}=\int_{0}^{N_{C}} d N=\int_{a_{i}}^{a_{c}} \frac{1}{C(\Delta K)^{m}} d a=\int_{a_{i}}^{a_{c}} \frac{d a}{C(\Delta \sigma \sqrt{\pi a} \cdot F)^{m}}= \\
\frac{1}{C(\Delta \sigma \sqrt{\pi} \cdot F)^{m}} \int_{a_{i}}^{a_{c}} \frac{1}{(\sqrt{a})^{m}} d a=\frac{2\left\{a_{i}^{-(m-2) / 2}-a_{c}^{-(m-2) / 2}\right\}}{(m-2) C(\Delta \sigma \sqrt{\pi} \cdot F)^{m}}
\end{gathered}
$$

where $a_{i}$ and $a_{c}$ are the initial and final fatigue crack lengths. $\Delta \sigma$ and $F$ are the nominal 


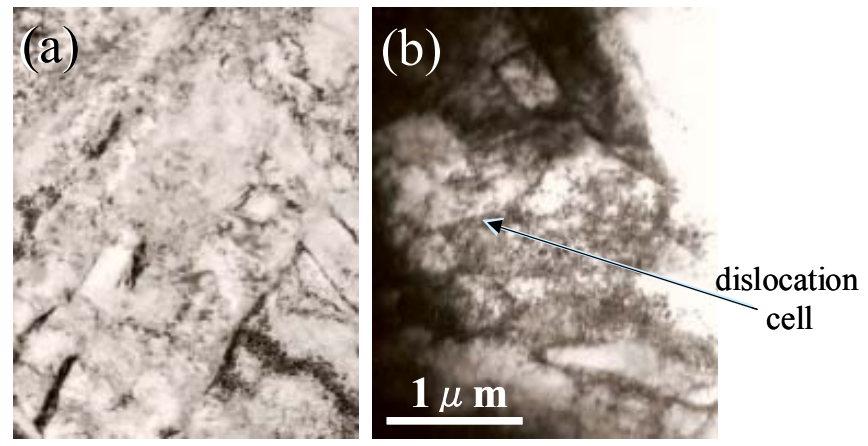

Fig. 13 TEM micrographs near the surface of the TS 970 MPa martensite specimen (M1); (a) initial, (b) at $\tau= \pm 500 \mathrm{MPa}$ to $N=9000$ cycles.
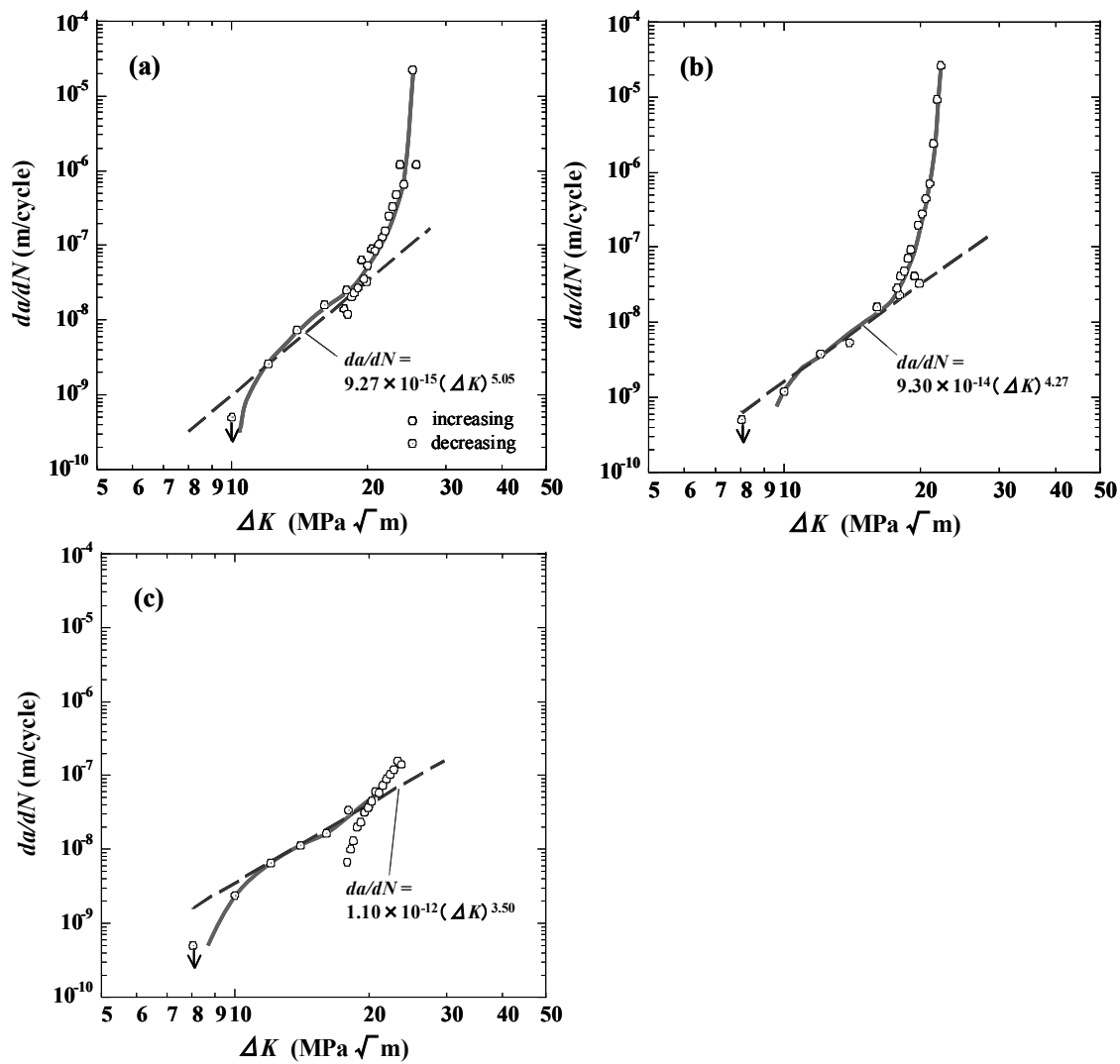

Fig. $14 d a / d N-\Delta K$ curves of the (a) FP2, (b) FM, and (c) M4 specimens.

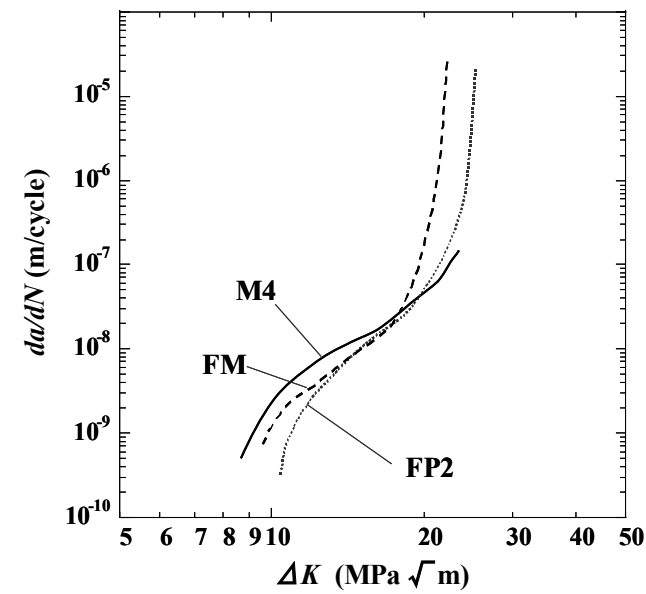

Fig. 15 Regression lines of the $d a / d N-\Delta K$ curves re-plotted from Fig.8. 
stress and the correction factor, respectively.

Based on Eq. (2), the crack propagation cycle number, $N_{c}$, from $a_{i}$ to $a_{c}$ was calculated as a function of $\Delta \sigma$ for (1) FP1, (2) MF and M1 (MF-M1), and (3) M3. The total fatigue cycle number of MF and M1 were approximately the same; thus, they were considered together. The calculation parameters are listed in Table 4.

In a previous study ${ }^{(8)}$, the propagation cycle number was calculated using reference $C$ and $m$ data ${ }^{(9)-(14)}$. In this study, we estimated $N_{c}$ based on the $C$ and $m$ value extracted from a linear approximation of the data in Fig. 8 in the Paris regime, which ranges from $\Delta K=12$ to $20 \mathrm{MPa} \sqrt{\mathrm{m}}$. For the $C$ and $m$ values for FP1, MF-M1, and M3 specimens, the values of FP2, FM, and M4 were respectively substituted. The $a_{i}$ value for FP1, MF-M1, and M3 was altered depending on their grain or packet size. 30, 20, and $10 \mu \mathrm{m}$ were substituted, respectively. The radius of the test specimen $(3 \mathrm{~mm})$ was adopted as the $a_{c}$ value. According to Eq. (3) ${ }^{(15)}$, the value of $F$ is 4.5916 when $\rho=0$.

$$
\boldsymbol{F}=4.5916 \exp \{-0.6759 \times(\boldsymbol{s} / \rho)\}
$$

where $s$ and $\rho$ are the crack length and the notch root radius, respectively. Furthermore, in this study, $F$ was multiplied by the crack correction factor for a surface semicircle $(0.728)^{(16)}$.

As seen in Fig. 6 - Fig. 13, the crack propagation stage includes both tensile and shear modes in the torsional fatigue test. However, crack growth rate in shear mode of the specimens used has not been separately evaluated. Nishizawa et al. reported that the crack growth rate of SUJ2 in Mode I and II overlaps around $d a / d N=10^{-8} \mathrm{~m} /$ cycle region $^{(17)}$. Thus, for the primary approximation, the crack growth rate in tensile mode was applied for the $N_{c}$ calculation in this study.

Figure 16 shows the relationship between $\Delta \sigma$ and the calculated propagation and initiation cycle number on a linear scale. The balance of the total fatigue cycle, i.e., the total cycle number minus the calculated propagation cycle number, is regarded as the initiation cycle number. Figure 17 shows the re-plotted data of Fig. 16. With an increase in $\Delta \sigma$, the ratio of the propagation cycle number increases as experimentally reported in a previous study ${ }^{(18)}$. It also appears that with an increase of material strength, the ratio of the propagation cycle number decreases as previously reported ${ }^{(19)}$.

Regardless of the initiation/propagation cycle ratio, which varies with $\Delta \sigma$, the total fatigue cycle number of MF and M1 are almost the same as shown Fig. 5. Therefore, it can be assumed that their initiation and propagation cycle numbers are individually almost the same. Thus, the growth of a discrete surface crack in the ferrite phase of the FM specimen shown in Fig. 6 (b) might be retarded by the surrounding martensite before the crack becomes an indiscrete initial crack. Consequently, the initial crack in FM seems to behave as if it is in a homogeneous microstructure, which is schematically described in ref. ${ }^{(20)}$.

As stated above, the simple calculation readily describes the tendency of initiation/propagation fatigue phenomena. However, it is based on many presumptions and approximations. Therefore, for further quantitative estimation and discussion, many other influencing factors such as the effect of stress mode, stress ratio, crack closure, crack coalescence, and surface residual stress must be clarified and taken into account.

\section{Low Temperature Toughness and Hydrogen Embrittlement Resistance of Martensitic Low Carbon Steel for Automotive Structural Parts}

Based on the above examination for fatigue endurance, martensite single phase is adopted as the basic microstructure for quench-type automotive structural parts. This is because it has advantages for some practical properties, such as low temperature toughness and hydrogen embrittlement resistance after quenching by providing a higher strength with a smaller amount of alloying elements than the dual-phase microstructure ${ }^{(20)}$. 
Table $4 \quad N_{c}$ calculation parameters.

\begin{tabular}{c|c|c|c|c|c|c}
\hline \multirow{2}{*}{ Material } & \multicolumn{3}{|c|}{ Crack growth parameter } & \multicolumn{2}{c|}{$\begin{array}{c}\text { Initial and final } \\
\text { crack length }\end{array}$} & \multirow{2}{*}{$\begin{array}{c}\text { Correction } \\
\text { factor, } F\end{array}$} \\
\cline { 2 - 6 } & $C(\mathrm{~m} /$ cycle $)$ & $m$ & Ref. & $a_{i}(\mu \mathrm{m})$ & $a_{c}(\mathrm{~mm})$ & \\
\hline FP1 & $9.27 \times 10^{-15}$ & 5.05 & FP2 & 30 & & \multirow{2}{*}{3.34} \\
\hline MF-M1 & $9.30 \times 10^{-14}$ & 4.27 & FM & 20 & 3 & \\
\hline M3 & $1.10 \times 10^{-12}$ & 3.50 & M4 & 10 & & \\
\hline
\end{tabular}
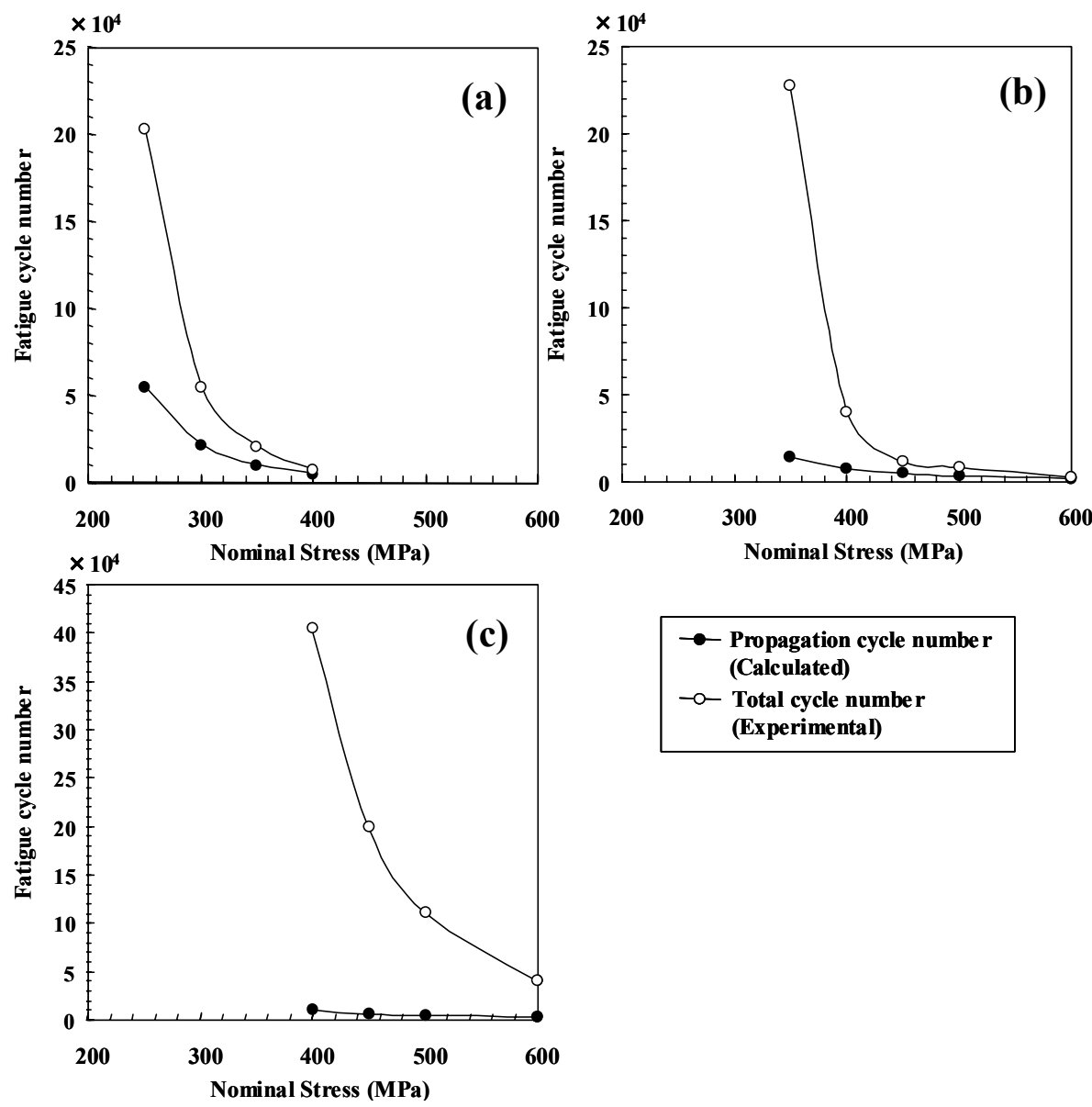

$\rightarrow$ Propagation cycle number (Calculated)

- - Total cycle numbe

(Experimental)

Fig. 16 The relationship between $\Delta \sigma$ and the calculated propagation and initiation cycle number of (a) FP1, (b) MF-M1, and (c) M3 specimens.

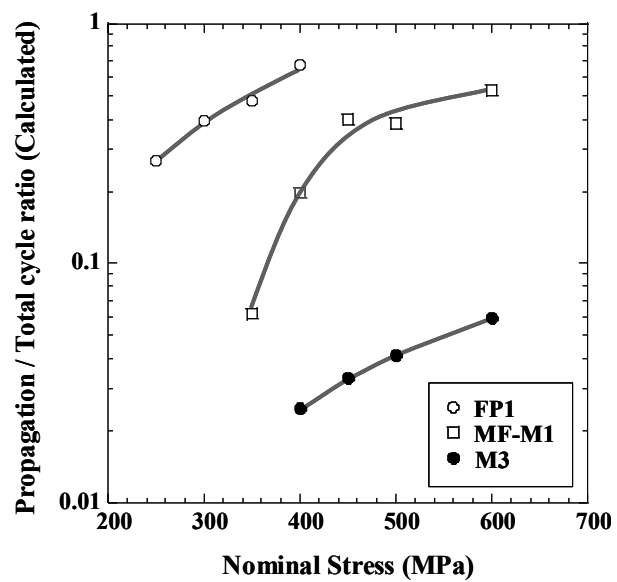

Fig. 17 Calculated propagation/total cycle ratio re-plotted from Fig. 16. 
A laboratory vacuum-fused steel having a base composition of $0.14-0.2 \% \mathrm{C}-0.3 \% \mathrm{Si}-$ $1.5 \% \mathrm{Mn}-0.01 \% \mathrm{P}-0.001 \% \mathrm{~S}-(\mathrm{Cr}, \mathrm{Mo})$ was hot-rolled, heated to an austenite single-phase region at $1223 \mathrm{~K}$, then quenched by water, and finally tempered at $473 \mathrm{~K}$. A $2 \mathrm{~mm}$ V-notched Charpy specimen was fabricated from this treated sheet material for evaluation of impact characteristics, and a four-point bending specimen was also made to carry out a four-point bending test ${ }^{(21)}$ under a loading stress of $1180 \mathrm{MPa}$ in $1 \mathrm{~N}$-hydrochloric acid.

Table 5 shows the Charpy impact characteristics and the four-point bending test results. All the tested specimens showed good impact characteristics, with $80 \mathrm{~J} / \mathrm{cm}^{2}$ or higher absorbed energy at $273 \mathrm{~K}$ and $213 \mathrm{~K}$ or lower fractured face transition temperature. The four-point bending test in $1 \mathrm{~N}$-hydrochloric acid produced no cracks over $240 \mathrm{~h}$, showing excellent hydrogen embrittlement resistance. Observation of the microstructure by SEM showed that all the specimens had fine carbide precipitation in a martensitic lath structure, as in ref. ${ }^{(21)}$. It is clarified that, similarly to the case of high strength cold-rolled steel sheets (22), the low carbon equivalent effectively gives excellent impact characteristics and hydrogen embrittlement resistance to hot-rolled-based martensite microstructures.

Table 5 Charpy impact properties and delayed fracture resistance of low-carbon martensite single-phase steel.

\begin{tabular}{|c|c|c|c|c|}
\hline \multirow{2}{*}{ HV10 } & \multicolumn{2}{|c|}{$\begin{array}{l}\text { Charpy impact properties } \\
\qquad(1 / 4 \text { size })\end{array}$} & $\begin{array}{l}\text { Delayed fracture } \\
\text { resistance* }\end{array}$ & \multirow{4}{*}{$\begin{array}{l}\text { - HV10: Vickers hardness obtained using } \\
\text { a 10kgf force } \\
\text { - vE0: Charpy absorbed energy at } 273 \mathrm{~K} \\
\text { - vTrs: Charpy fracture appearance } \\
\text { transition temperature } \\
\text { *:Loading stress }=1180 \mathrm{MPa} \\
\text { in } 1 \mathrm{~N} \text { hydrochloric acid solution }\end{array}$} \\
\hline & $\begin{array}{c}\mathrm{vE} 0 \\
\left(\mathrm{~J} / \mathrm{cm}^{2}\right)\end{array}$ & $\begin{array}{l}\mathrm{vTrs} \\
(\mathrm{K})\end{array}$ & $\begin{array}{l}\text { Time to fracture } \\
\text { (h) }\end{array}$ & \\
\hline 431 & 113 & 173 & $>240$ & \\
\hline 454 & 103 & 193 & $>240$ & \\
\hline
\end{tabular}

\section{Conclusions}

The effect of the microstructure of martensitic carbon steel on torsional fatigue endurance was investigated, taking into consideration the application of high strength steel electric resistance welded (ERW) tubes to automotive structural parts.

(1) Torsional fatigue endurance was found to monotonously increase with an increase in tensile strength in the range of 540 to $1380 \mathrm{MPa}$. The martensite and ferrite dual-phase specimen, MF, and the martensite single-phase specimen, M1, both having a tensile strength of about $950 \mathrm{MPa}$, showed almost the same fatigue endurance independent of the loading stress level.

(2) Based on the crack growth test results, the propagation cycle number was calculated using the Paris law. With an increase of $\Delta \sigma$ and with a decrease in material strength, the ratio of the propagation cycle number was found to increase using this calculation.

(3) In addition to fatigue properties, low-temperature toughness and hydrogen embrittlement resistance were also evaluated for the low-carbon martensite single-phase steel.

\section{Acknowledgements}

The authors are deeply indebted to Mr. Shota Hashimoto and Mr. Michitaka Sato of JFE Techno-Research Corporation for supporting the fatigue crack growth testing.

\section{References}

(1) Schaik, M. V., 2002, "ULSAB-Advanced Vehicle Concepts-Chassis and Suspension," SAE Paper 2002-01-0045, pp. 1-11.

(2) Kawashima, N., 2002, "Development of Light-Weighted Chassis for ES3 Vehicle," Toyota 
Tech. Rev., Vol. 52, pp. 42-47.

(3) Nasu, K., 2000, "Newly developed automotive parts with tube hydroforming," Proc. Int. Joint Symp. of 195th Tech. of Plasticity, Osaka, Japan, pp. 209-211.

(4) Kurita, M. and Toyama, K., 1994, "Effect of Strengthening Mechanisms on Fatigue Properties of Ferrite-Pearlite Hot-Rolled Sheet Steel," Tetsu-to-Hagané, Vol. 80, pp. 66-71.

(5) Kurita, M., Toyama, Nomura, S. and Kunishige, K., 1995, "Effect of Strengthening Mechanism on Fatigue Properties of Dual Phase Sheet Steel,” Tetsu-to-Hagané, Vol. 81, pp. 1091- 1096.

(6) Chen, D. L., Wang, Z.G., Jiang, X. X., Ai, S. H. and Shih, C. H., 1989, "The Dependence of Near-threshold Fatigue Crack Growth on Microstructure and Environment in Dual-phase Steels," Mater. Sci. Eng., Vol. A108, pp. 141-151.

(7) Wang, Z.G. and Ai, S.H., 1999, "Fatigue of Martensite-Ferrite High Strength Low-alloy Dual Phase Steels," ISIJ Int., Vol. 39, pp. 747-759.

(8) Toyoda, S., Ishiguro,.Y., Kawabata, K. and Sakata, K., 2007, "Effect of Microstructure on Torsional Fatigue Endurance of Martensitic Carbon Steel," Proc. of The 1st Int. Symp. on Steel Science, Kyoto, Japan, pp. 211-214.

(9) Ouchi, H. and Kobayashi, J., 1990, "Effects on Environmental Variables on Fatigue Crack Growth Rate in 660MPa Steel," Tetsu-to-Hagané, Vol. 76, pp. 446-453.

(10) Takemata, H., Ishizaka, J. and Iwadate, T., 1990, "Fracture Toughness and Crack Propagation Rate of High Strength Ni-Cr-MO-V Steel," CAMP-ISIJ, Vol.3, pp. 1999.

(11) Shimoyama, T., Manabe, T. and Iwata, A., 2002, "Fatigue Strength and Fatigue crack Propagation Behavior of High Strengh Steels," Tec. Rep. Fukui Inst. Tec., Vol. 32, pp. 115-122.

(12) Miyazaki, T., Noguchi, H. and Ogi, K., 2004, "Quantitative evaluation of the fatigue limit of a metal with an arbitrary crack under a stress controlled condition,” Int. J. Fract., Vol. 129, pp. 21-38.

(13) Murakami, Y., Nomoto, T., Ueda, T. and Murakami, Y., 2000, "On the mechanism of fatigue failure in the superlong life regime. PartII: a fractographic investigaion," Fatigue Fract. Engng. Mater. Struct., Vol. 23, pp. 903-910.

(14) Zhen, L., 1994, "Estimation of fatigue crack propagation rate in steel," Eng. Fract. Mech., Vol. 48, pp.339-345.

(15) Kfouri, A.P., 1970, "The elasto-plastic analysis of continua by finite element methods," Ph.D thesis Univ. of Cambridge, pp. 132-139.

(16) Tanaka, K., Akiniwa, Y., Morita, K. and Wakita, M., 2008, "Prediction of Fatigue Thresholds of Steels with surface Defects," J. of Soc. Mat. Sci., Japan, Vol. 57, pp.140-146.

(17) Nishizawa, H. and Ogawa, T., 2005, "Mode II Fatigue Crack Growth Characteristics and Experimental Evaluation of the Crack Driving Force," J. of Soc. Mat. Sci., Japan, Vol. 54, pp.1295-1300.

(18) Chen, X., Ohkawa, I. and Misumi, M., 2004, "Effect of Mean Stress on Torsional Fatigue Behavior of a Medium Carbon Steel,” J. of Soc. Mat. Sci., Japan, Vol. 53, pp.199-206.

(19) Yokomaku, T. and Kinefuchi, M., 1993, "Effect of Microstructure on Crack Closure in Small Fatigue Crack Growth,” Proc. of Solid Mech., JSME., Osaka, Japan, pp.113-114.

(20) Toyoda, S., Aratani, M., Kawabata, Y., Suzuki., Sakata, K., Gunji, M. and Sato, A., 2006, "Development of high strength steel tubes with excellent formability for automotive suspension parts," Proc. of 31th FISITA, Yokohama, F2006M146.

(21) Toyoda, S., Ishiguro, Y., Kawabata, Y., Sakata, Kei., Sato, A. and Sakai, J., 2008, "Effect of $\mathrm{Cu}$ Addition on Delayed Fracture Resistance of Low Carbon Steel for 1470MPa Grade Electric Resistance Welded Tube,” ISIJ Int., Vol. 48, pp. 640-648.

(22) Nagataki, Y., Hosoya, Y. and Okita, T., 1996, "Effect of Microstructure on Bendability and Delayed Fracture Resistance of Ultra-High-Strength Steel Sheet," Proc. of 29th ISATA, London, 96NM080. 